\title{
Preparation, Characterization, and Optimization of Folic Acid-Chitosan-Methotrexate Core-Shell Nanoparticles by Box-Behnken Design for Tumor-Targeted Drug Delivery
}

\author{
Hamid Reza Naghibi Beidokhti, ${ }^{1}$ Reza Ghaffarzadegan, ${ }^{2}$ Sasan Mirzakhanlouei, ${ }^{2}$ \\ Leila Ghazizadeh, ${ }^{3}$ and Farid Abedin Dorkoosh ${ }^{4,5,6}$
}

Received 6 July 2015; accepted 19 October 2015; published online 19 February 2016

\begin{abstract}
The objective of this study was to investigate the combined influence of independent variables in the preparation of folic acid-chitosan-methotrexate nanoparticles (FA-Chi-MTX NPs). These NPs were designed and prepared for targeted drug delivery in tumor. The NPs of each batch were prepared by coaxial electrospray atomization method and evaluated for particle size (PS) and particle size distribution (PSD). The independent variables were selected to be concentration of FA-chitosan, ratio of shell solution flow rate to core solution flow rate, and applied voltage. The process design of experiments (DOE) was obtained with three factors in three levels by Design expert software. Box-Behnken design was used to select 15 batches of experiments randomly. The chemical structure of FA-chitosan was examined by FTIR. The NPs of each batch were collected separately, and morphologies of NPs were investigated by field emission scanning electron microscope (FE-SEM). The captured pictures of all batches were analyzed by ImageJ software. Mean PS and PSD were calculated for each batch. Polynomial equation was produced for each response. The FE-SEM results showed the mean diameter of the core-shell NPs was around $304 \mathrm{~nm}$, and nearly $30 \%$ of the produced NPs are in the desirable range. Optimum formulations were selected. The validation of DOE optimization results showed errors around 2.5 and $2.3 \%$ for PS and PSD, respectively. Moreover, the feasibility of using prepared NPs to target tumor extracellular $\mathrm{pH}$ was shown, as drug release was greater in the $\mathrm{pH}$ of endosome (acidic medium). Finally, our results proved that FAChi-MTX NPs were active against the human epithelial cervical cancer (HeLa) cells.
\end{abstract}

KEY WORDS: box-Behnken design; coaxial electrospray; folic acid-chitosan nanoparticles; methotrexate; optimization.

\footnotetext{
${ }^{1}$ Department of Pharmaceutical Engineering, Faculty of Engineering, University of Tehran, Tehran, Iran.

${ }^{2}$ Medical Plants Research Center, Institute of Medical Plants, ACECR, Karaj, Iran.

${ }^{3}$ Pasteur Institute of Iran, National Cell Bank of Iran, Tehran, Iran.

${ }^{4}$ Medical Biomaterial Research Center, Tehran University of Medical Sciences, Tehran, Iran.

${ }^{5}$ Department of Pharmaceutics, Tehran University of Medical Sciences, Tehran, Iran.

${ }^{6}$ To whom correspondence should be addressed. (e-mail: Drorkoosh@tums.ut.ac.ir)
}

\begin{abstract}
ABBREVIATIONS: FA-Chi-MTX NPs, Folic acid-chitosanmethotrexate nanoparticles; PS, Particle size; PSD, Particle size distribution; FTIR, Fourier transform infrared spectroscopy; DOE, Design of experiments; ALL, Acute lymphoblastic leukemia; FRs, Folate receptors; DCC, N, N'-dicyclohexylcarbodiimide; NHS, Nhydroxysuccinimide; TFE, 2, 2, 2-Trifluoroethanol; TEA, Triethylamine; DMSO, Dimethyl sulfoxide; DCU, Dicyclohexylurea; kDa, Kilodalton; DMF, Dimethylformamide; PBS, Phosphate-buffered saline; FE-SEM, Field emission scanning electron microscope; ANOVA, Analysis of variance; MLRA, Multiple linear regression analysis.
\end{abstract}

\section{INTRODUCTION}

There is an increase in application of nanotechnology in the field of pharmaceutics and drug delivery. Development of drug nano-micro particles result in significant changes in targeted drug delivery to the desired tissues.

Methotrexate is widely used in treatment of various diseases including acute lymphoblastic leukemia (ALL), osteosarcoma, non-Hodgkin's lymphoma, psoriasis, head and neck cancer, lung cancer, breast cancer, and other trophoblastic tumors (1). However, undesirable side effects of methotrexate such as normal cell toxicity, drug resistance, renal toxicity, bone marrow inhibition, liver toxicity, and acute and chronic obstructive pulmonary diseases have been reported (2). Methotrexate is known as a strong classic anticancer agent and used as monotherapy or in combination with other anticancer drugs in multidrug chemotherapy regimens (3). It has a wide range of activities in cytostatic activities, especially when high doses are associated with the release of folinic acid (4-6). Serum concentrations of methotrexate quickly drop when it is directly injected into the bloodstream (7). These problems can be solved by trapping the drug in the colloidal forms like nanoparticles. On the other hand, the therapeutic index and drug 
activity period increase by incorporating the drug into carrier systems. The colloidal carrier systems may decrease the drug's cytotoxicity, increase the influence of drugs, and also they can lead drugs to the desired sites. Moreover, drug carriers prevent the decomposition of drugs and in most cases results to more solubility of drugs. Furthermore, nano-scale drug delivery systems caused better absorption of the drug through the digestive organs. Polymeric nanoparticles have been widely used as targeted drug delivery (8-10), and greatly reduce unwanted side effects and improve the effectiveness of treatment $(11,12)$.

Chitosan due to its unique properties such as biocompatibility, biodegradability, non-toxicity, bio-adhesion, and cationic properties has recently found extensive pharmaceutical and medicinal applications (13-15). Many studies have been published for the application of this natural polymer in order to encapsulate nanoparticles, and deliver it to the targeted tumor site (16-27). Therefore, chitosan nanoparticles are considered to be promising colloidal drug carriers for targeted drug delivery to specific sites, as well as in the treatment of cancer, delivery of vaccines, and gene delivery applications $(28,29)$. Chitosan is a linear amino-polysaccharide composed of randomly distributed $\beta$-(1-4)-linked D-glucosamine (deacetylated unit) and N-acetyl-D-glucosamine (acetylated unit). The presence of reactive functional groups in chitosan creates enormous opportunities for chemical modifications which contain wide range of derivatives such as $\mathrm{N}, \mathrm{N}, \mathrm{N}-$ trimethyl chitosan, carboxy alkyl chitosan, chitosan with cyclodextrin interfaces, and etc. These kinds of derivatives were designed for the improvement of natural chitosan properties $(30,31)$. Chitosan nanoparticles usage was limited due to its low efficiency in specific targeting (32). The effective way to improve the targeting ability of chitosan nanoparticles is to conjugate them with chemical or biological ligands which contain antibodies or targeted agents with low molecular weight, such as folate (33). Folate is generally known as an effective agent for tumor targeting, and it is generally conjugated with nanoparticles due to its ability to establish a special link with folate receptors (FRs) (34). Conjugated folates are covalently linked via their c-carboxyl derivatives component, which can justify the high affinity of folate ligand. Kinetics of cellular uptake of folate-conjugated compounds by folate receptors (FRs) is similar to free folate (35). In addition, folic acid can prevent nervous system toxicity even at very high doses of methotrexate (36-38). Folate receptor is a valuable therapeutic target which is strongly affected in different types of cancer. Folate is considered as targeting ligand for various anticancer drugs, in case of preventing from unwanted attacking to healthy tissues. Folate enters targeted tumors cells with the assistance of cellular receptors via the endocytosis process and thereby enhances cellular uptake $(39,40)$. In conclusion, nanoparticles which were conjugated with folate are ideal polymeric carriers for targeted drug delivery to tumors.

In recent years, coaxial electrospray technique (which is derived from a single axis electrospraying technique) was used to prepare core-shell nanoparticles. In a coaxial electrospraying system, two or more capillary tube binds to a uniform electric potential. Active substance flows in the inner capillary tube, and coating polymer flows in the external capillary tube. The coaxial liquid beams drop out from Taylor cone vertex, and they convert to capsules or multilayered drops. Electrospray is a direct and single-step method for the preparation of solid nanoparticles and also can be done with mild process conditions (41-45).

High potential of coaxial electrospraying new method for preparing multilayered nanoparticles has formed the basis of this study. For the purpose of reducing the side effects of anticancer drugs, a core-shell nanoparticle model was chosen. This drug delivery system consists of chitosan polymer conjugated with folic acid as shell coater and methotrexate as anticancer agent which will be encapsulated in the core. In this regard, due to the high cost of raw materials and reducing time-consumption, design of experiments (DOE) was used. By using DOE software, the minimum numbers of required experiments in the operating range were determined. Optimization of process conditions for selected independent variables (A: applied voltage, B: ratio of shell solution flow rate to core solution flow rate, $\mathrm{C}$ : concentration of FA-Chi solution) were done by Design expert software. For this purpose, a formulation with the best desirability factor was selected and its batch data was examined. The results were compared with estimated results which were produced by software. Moreover, the cytotoxicity of the FA-Chi-MTX NPs was assessed against tumor and non-tumor cell lines.

\section{MATERIALS AND METHODS}

\section{Materials}

Chitosan medium (degree of deacetylation 95\%) was purchased from Primex, Iceland. Methotrexate was purchased from MP biomedicals, USA. N, N'-dicyclohexylcarbodiimide (DCC), N-hydroxysuccinimide (NHS), and folic acid (FA) were purchased from Merck, Germany. Pentasodium tripolyphospate (TPP) and 2, 2, 2-trifluoroethanol (TFE) were purchased from Sigma-Aldrich, Germany. All materials were in analytical grade and used with no additional purification process.

\section{DoE by Box-Behnken Design}

According to pre-tests, three independent factors in three levels were selected. The independent variables were coded as shown in Table I. By using a Box-Behnken model with three central points, 15 experimented batches were randomly selected and data were generated for each set of batches (Table II).

\section{Preparation of FA-NHS ester}

Folic acid $(1 \mathrm{~g})$ and triethylamine (TEA) $(0.5 \mathrm{ml})$ were added to $40 \mathrm{~mL}$ of dimethyl sulfoxide (DMSO). The solution was stirred in the dark overnight at chamber temperature (around $20 \mathrm{~h})$. DCC $(0.5 \mathrm{~g})$ and NHS $(0.5 \mathrm{~g})$ was added to the container and stirring procedure continued for next $20 \mathrm{~h}$ in the dark (46).

The first step of reaction has produced a by-product called dicyclohexylurea (DCU) (Fig. 1). DCC is soluble in many organic solvents while the DCU by-product is generally insoluble and easily removed by filtration. Then, yellow FANHS ester was precipitated by dropwise adding of solution containing ether and $30(\mathrm{v} / \mathrm{v}) \%$ acetone. For the initial 
Table I. Independent Variables with Their Upper and Lower Levels

\begin{tabular}{lccc}
\hline \multicolumn{1}{c}{ Name } & Unit & -1 Level & +1 Level \\
\hline Voltage (v) & $\mathrm{V}$ & 15 & 25 \\
Ratio & & 3 & 5 \\
Concentration (\%) & $\%$ & 0.1 & 1.0 \\
\hline
\end{tabular}

filtrations, syringe filters were used and then product was dried under vacuum.

\section{Fa-Chi Synthesis}

Stoichiometric of reaction yield was considered to be $50 \%$. For the purpose of FA-Chi synthesis, the following solutions were made: A- yellow NHS ester of FA was added to $10 \mathrm{~mL}$ of DMSO and B- $0.02 \mathrm{~g}$ of chitosan was dissolved in $10 \mathrm{~mL}$ of buffer acetate $(\mathrm{pH}=4.7)$.

Solution A was dropwise added to solution B under stirring condition. Stirring was continued overnight at room temperature. The achieved solution was brought to $\mathrm{pH}=9$ by $\mathrm{NaOH}$ solution $(1 \mathrm{M})$. In order to separate the conjugated polymers from unreacted materials, the reaction mixtures were dialyzed (cut-off $=12 \mathrm{kDa}$ ) against phosphate-buffered saline (PBS) $(\mathrm{pH}=7.4)$ for 3 days, and then against deionized water for another 3 days in order to remove DMSO. The final purification of the polymer was obtained by freeze drying process (47-50).

\section{Fourier Transform Infrared Spectroscopy (FTIR)}

In order to determine the chemical structure of FA-Chi, all samples were characterized via ATR-FTIR by mounting the ATR accessory in the spectrometer's sample compartment. All spectra were obtained from 600 to $2000 \mathrm{~cm}^{-1}$ at chamber temperature. Bruker vertex $80 \mathrm{v}$ Fourier transform infrared spectrometer instrument was used.

\section{Preparation of FA-Chi-MTX Nanoparticles Using Coaxial Electrospray}

Methotrexate dispersed in dimethylformamide (DMF) solution was used as the core solution, and FA-chitosan solution was the shell solution. Coaxial electrospray is a singleand one-step method which can be done under mild process condition. This technique produces very small aerosol particles, and disperses produced NPs on the charged plate due to Coulomb's repulsion law. The flow rate was fixed at $0.1 \mathrm{~mL} / \mathrm{h}$ for the core solution and the range of 0.3 to $0.5 \mathrm{~mL} / \mathrm{h}$ for the shell solution. As shown in Fig. 2, the positive electrode was connected to the coaxial nozzle, while the negative electrode was connected to the aluminum foil, which was placed vertical to the nozzle as a deposition target. Fifteen centimeters was chosen as the distance between the nozzle and aluminum foil. The inner and outer nozzle diameters were 0.6 and $1.2 \mathrm{~mm}$, respectively. All preparations were carried out in a laboratory at chamber temperature, and the humidity was controlled at lower than $30 \% \mathrm{RH}$.

\section{Morphology Analysis}

Morphology of prepared core-shell nanoparticles was determined by field emission scanning electron microscope (FESEM). Hitachi S 4160 FE-SEM with a resolution of $2.5 \mathrm{~nm}$ in $30 \mathrm{kV}$ was used. The magnification of this FE-SEM model is about 300,000 and in comparison, approximately three times the normal scanning electron microscope.

\section{Particle Size Measurement}

The images captured by scanning electron microscopy were analyzed with ImageJ software. This software is able to measure the particle diameter in different scales. By using this capability, the diameter of nanoparticles with acceptable sphericity was estimated and the results were implemented in Microsoft Excel Software.

Table II. Experimental Design in 15 Runs and the Correspondent Responses

\begin{tabular}{|c|c|c|c|c|c|c|}
\hline Std & Run & $\begin{array}{l}\text { Factor1 A: } \\
\quad \text { voltage }(\mathrm{kV})\end{array}$ & $\begin{array}{l}\text { Factor2 } \\
\text { B: ratio }\end{array}$ & $\begin{array}{l}\text { Factor3 C: } \\
\quad \text { concentration (\%) }\end{array}$ & $\begin{array}{l}\text { Response1 } \\
\quad \text { particle size (nm) }\end{array}$ & $\begin{array}{l}\text { Response2 } \\
\text { PSD (\%) }\end{array}$ \\
\hline 12 & 1 & 20 & 5 & 1.00 & 311 & 33 \\
\hline 15 & 2 & 20 & 4 & 0.55 & 309 & 29 \\
\hline 8 & 3 & 25 & 4 & 1.00 & 314 & 21 \\
\hline 4 & 4 & 25 & 5 & 0.55 & 295 & 30 \\
\hline 14 & 5 & 20 & 4 & 0.55 & 315 & 30 \\
\hline 1 & 6 & 15 & 3 & 0.55 & 352 & 29 \\
\hline 3 & 7 & 15 & 5 & 0.55 & 269 & 31 \\
\hline 11 & 8 & 20 & 3 & 1.00 & 257 & 28 \\
\hline 9 & 9 & 20 & 3 & 0.10 & 350 & 32 \\
\hline 13 & 10 & 20 & 4 & 0.55 & 312 & 27 \\
\hline 7 & 11 & 15 & 4 & 1.00 & 349 & 39 \\
\hline 6 & 12 & 25 & 4 & 0.10 & 303 & 31 \\
\hline 10 & 13 & 20 & 5 & 0.10 & 300 & 29 \\
\hline 2 & 14 & 25 & 3 & 0.55 & 269 & 34 \\
\hline 5 & 15 & 15 & 4 & 0.10 & 261 & 24 \\
\hline
\end{tabular}




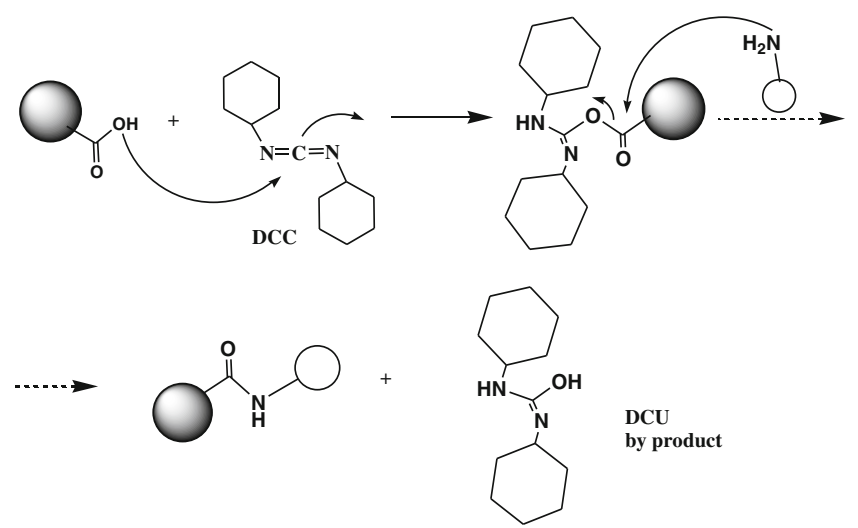

Fig. 1. Dcc coupling reaction mechanism

\section{Particle Size Distribution Measurement}

The particle size distribution (PSD) was produced by Microsoft Excel software and calculated by using the following equation:

$\operatorname{PSD}=\frac{x}{T}$

where $x$ is the number of appropriate particles and $T$ is the total number of particles. Values obtained as the PSD are considered for each batch of tests separately.

\section{Design of Experiments}

Analysis of the results was performed by Stat-Ease Design Expert software. After placing the response data in the application, and checking all polynomial models fitted to the data, cube model (stepwise) was statistically significant and proposed to run DOE. $F$ values, $P$ value, and model $F$ value for average particle size and particle size distribution were obtained from analysis of variance (ANOVA). Model selection, polynomial equations, and other statistical data are given in Table V. Fifteen coefficients $\left(\beta_{1}\right.$ to $\left.\beta_{15}\right)$ were calculated using $\beta_{0}$ as intercept. The predicted models were defined with cubic polynomial functions as follows:

$$
\begin{aligned}
Y=\beta_{0} & +\beta_{1} \mathrm{~A}+\beta_{2} \mathrm{~B}+\beta_{3} \mathrm{C}+\beta_{4} \mathrm{AB}+\beta_{5} \mathrm{AC}+\beta_{6} \mathrm{BC}+\beta_{7} \mathrm{~A}^{2} \\
& +\beta_{8} \mathrm{~B}^{2}+\beta_{9} \mathrm{C}^{2}+\beta_{10} \mathrm{~A}^{2} \mathrm{~B}+\beta_{11} \mathrm{~A}^{2} \mathrm{C}+\beta_{12} \mathrm{~B}^{2} \mathrm{~A}+\beta_{13} \mathrm{~B}^{2} \mathrm{C} \\
& +\beta_{14} \mathrm{C}^{2} \mathrm{~A}+\beta_{15} \mathrm{C}^{2} \mathrm{~B}
\end{aligned}
$$

where $\beta_{0}$ is the arithmetic average of all 15 responses, and $A, B$, and $C$ are the coded levels of the independent variable. This form of equation was used to estimate responses. Coefficients of polynomial equations are determined by using multiple linear regression analysis (MLRA) to calculate particle size and particle size distribution.

\section{Optimization Data Analysis and Model Validation}

The results of polynomial regression were described by 3D graphs and contour plots and also optimized formulation was selected. Predicted responses were selected based on desirability factors. Criteria for selecting the optimal formulations were selected according to maximum amount for PSD and minimum amount for particle size.

The optimal formulation was selected as a checkpoint to validate response surface method (RSM). MTX-FA-Chi nanoparticles were formulated based on optimal formulation. Percent errors were calculated according to obtained values for the responses and these values were compared with estimated values. Finally, correlation plots were plotted separately for each response.

\section{Drug Loading and Encapsulation Efficiency}

High-performance liquid chromatography (HPLC) was used to measure the drug association efficiency and the amount of encapsulated drug. The prepared solutions are conducted on a Dikma C18 column $(250 \mathrm{~mm} \times 4.6 \mathrm{~mm}, 5$ $\mu \mathrm{m})$ at $35^{\circ} \mathrm{C}$. An aqueous solution of acetonitrile and water in isocratic mode $(\mathrm{pH}=5.7)$ was used as mobile phase, and the flow rate was $0.3 \mathrm{~mL} / \mathrm{min}$. The measurements were carried out by calculating the peak areas in relation to those of standards chromatographed under same conditions. Standard calibration curves were prepared by using of the TPP aqueous solution as solvent. Data were given as mean \pm standard deviation. The data were calculated as follows:

Drug loading $(\mathrm{DL})=\frac{\text { MTX detected }(\mathrm{gr})}{\text { nanoparticles total weight }}$

Encaptulation efficiency $(\mathrm{EE})=\frac{\text { MTX detected }(\mathrm{gr})}{\text { MTX total weight }}$

\section{In Vitro Release Studies}

In vitro release study of the drug-loaded core-shell NPs were tested by dialysis method. The FA-Chi-MTX NPs were carried out in PBS at $\mathrm{pH} 7.4$ (pH of blood) and $\mathrm{pH} 5.0$ ( $\mathrm{pH}$ of endosome) for $24 \mathrm{~h}$. The NPs were placed in a dialysis bag (cut-off $=12 \mathrm{kDa}$ ) at $37^{\circ} \mathrm{C}$ under stirring condition $(100 \mathrm{rpm})$. At defined schedule times, $2 \mathrm{~mL}$ of medium was replaced with fresh medium. The replaced samples were withdrawn and analyzed by HPLC. The in vitro drug release profile was determined by measuring the cumulative amount of the MTX released over an experimental time period by using the following equation:

Cumulative release $(\mathrm{CR})=\frac{\mathrm{Wt}}{\mathrm{Wi}}$

where $\mathrm{Wt}$ is the amount of drug released at the time $t$ and Wi is the initial amount of the drug encapsulated in the NPs. The amount of MTX released was measured by UV spectrophotometer at $303 \mathrm{~nm}$. Each batch of samples was tested in triplicate.

\section{Cell Cultures and Cell Cytotoxicity}

For cell cytotoxicity measurement, the tumor cell lines HeLa (human epithelial cervical cancer) and non-tumor cell line HGF-1 (human gingival fibroblast normal cell line) were seeded at a density of $1 \times 10^{4}$ cells/well $(0.1 \mathrm{~mL})$ into 60 


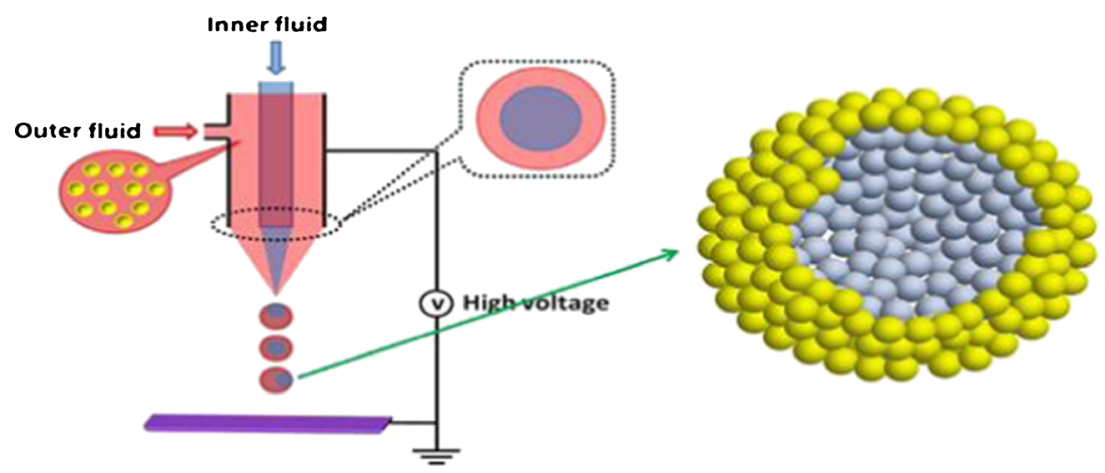

Fig. 2. The schematic figure of coaxial electrospray device and the core-axial nanoparticle

central wells of 96-well tissue culture plates in $100 \mu \mathrm{l}$ of complete culture medium at body temperature $\left(37^{\circ} \mathrm{C}\right)$. The culture medium was removed after incubation. The medium containing FA-Chi-MTX NPs were incubated at drug concentrations of $0.1,1,5,15$, and $25 \mu \mathrm{g} / \mathrm{mL}$. MTT assay was used to measure the cell viability at different time periods. The absorbance was measured by the microplate reader (wavelength $=545 \mathrm{~nm}$ ). The cytotoxicity result was measured as follows:

Cytotoxicity $(\%)=\frac{x-y}{x} \times 100$

where $x$ is the absorbance of the cells incubated with the culture medium and $y$ is the absorbance of the cells incubated with FA-Chi-MTX NPs. All samples were evaluated five times.

\section{RESULTS AND DISCUSSION}

\section{Characterization of FA-chi}

In order to synthesize FA-chitosan, the first step was the FA-NHS ester formation (the synthesis reaction of FA-NHS ester can be seen in the Fig. 3a). After purification and extraction, FA-NHS ester powder was reacted with chitosan (Fig. 3b). Finally, the FA-chitosan substance was produced. After lyophilization, folate-chitosan powder was kept in appropriate conditions until the electrospraying process stage.

Conjugation reaction of folic acid and chitosan occurred in an environment which consists of DCC/NHS and in the presence of DMSO. FTIR was used to determine the chemical structure of FA-chi which can confirm the amide bond $(\mathrm{CONH})$ in the folic acid-chitosan structure (Fig. 4). The range between two peaks of 1640 and $1565 \mathrm{~cm}^{-1}$ in chitosan FTIR graph indicates strong bond vibrations of $(\mathrm{NH})$ and $\left(\mathrm{NH}_{2}\right)$, respectively. Folic acid diagram has a severe decline at $1695 \mathrm{~cm}^{-1}$, which represents the $(\mathrm{COOH})$ bond and also it has another decline at $1605 \mathrm{~cm}^{-1}$ which shows the (C-C) bond. In comparison with the chitosan diagram, the FA-Chi spectra has significant difference at $1686 \mathrm{~cm}^{-1}$, which may be due to the formation of the amide bond between the amino group of chitosan and the carboxyl group of folic acid. The potential formation of these bonds has occurred by DCC/NHS activation. These differences can be seen in folic acid diagram at
$1609 \mathrm{~cm}^{-1}$ as well. These results confirmed that folic acid was chemically conjugated to the chitosan backbone.

\section{Formulation Variables of FA-Chi-MTX NPs}

In the electrospraying process, several factors affected the quality and size of NPs. These factors include effect of solvent properties (concentration, conductivity, surface tension, stability of the electrospray behavior, and interfacial surface tension between the inner and outer liquids), effect of applied voltage, needle diameters of core and shell solutions, ratio of flow rates between the core and shell solutions, and the distance between the nozzle and aluminum foil in which the latter one has already been studied (41,44,45,51-53). Three independent factors like concentration, applied voltage, and ratio of flow rates between the core and shell solutions which can have the greatest impact on particle size were selected and studied further.

\section{FA-Chi Concentration}

Folic acid-chitosan solution concentration plays a vital role in the feasibility of the electrospray process. Change in solvent concentration affects the viscosity and surface tension of the solutions, and we know these two factors could determine the quality of droplets in the electrospray process.

At concentrations less than $1 \mathrm{wt} \%$, the droplets are formed rapidly and solution sputters without formation of suitable cone-jet and thereby the droplets will not form into the desired shape. If the concentration considered between 1.5 to $2 \mathrm{wt} \%$ the mixture of beads and fibers observed. Based on these observations, the use of higher concentrations in the electrospray process makes it impossible. Thus, a concentration of $1 \mathrm{wt} \%$ would be desirable and best efficiency occurs at this level (51).

In contrast with pure chitosan, the solubility of surfacemodified chitosan with folate is significantly reduced. This evidence happened since the amino groups of chitosan were blocked in the conjugation process. Considering the experiences of others in this field, a solution of water/TFE/acetic acid, with ratios of 4:4:3 respectively was used as shell solvent $(51,53)$.

To assess the effect of concentration, two separate solutions were prepared: 
$\mathbf{a}$<smiles>Nc1nc(O)c2nc(CNc3ccc(C(=O)N[C@@H](CCC(=O)O)C(=O)O)cc3)cnc2n1</smiles>

FA
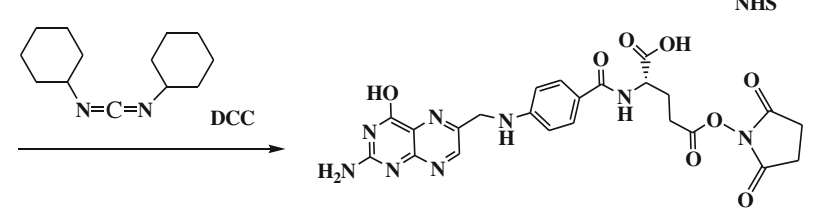

NHS-Ester of FA

b
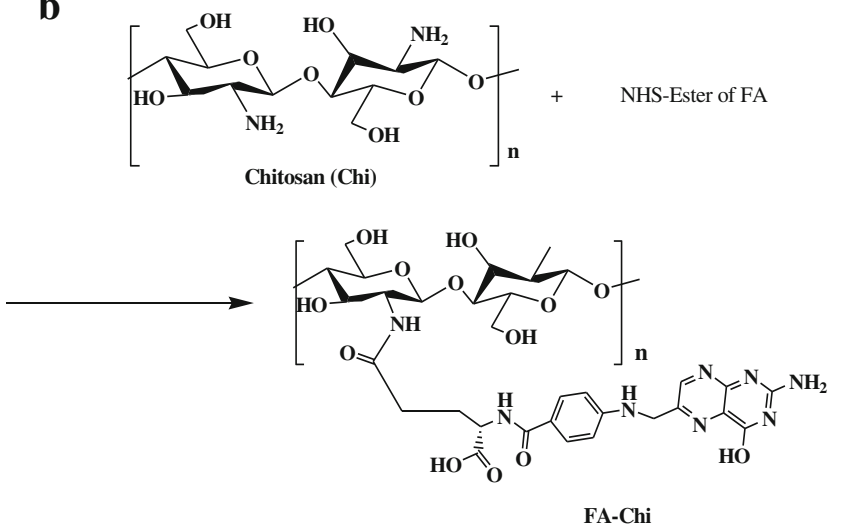

Fig. 3. Synthesis process of FA-Chi. a Formation reaction of NHS ester of FA, b Formation of FA-Chi

A-Solution contains $1 \mathrm{wt} \%$ of chitosan-folic acid in the special solvent (water/TFE/acetic acid, with ratios of $4: 4: 3$, respectively).
B- Solution of $1 \mathrm{wt} \%$ chitosan in acetic acid was prepared.

Concentration levels are defined as below:

Lower limit: Solution containing $90 \%$ by volume of solution A and $10(v / v) \%$ of solution B. The reported number is 0.1 .

Upper limit: $100 \%$ of solution B. The reported number is 1 .

\section{Effects of Applied Voltage}

Three levels were used for this factor. The selection of these levels was based on the three categories:

A- The previous reports which were reviewed in the stage of literature reviews

B- Experiences of electrospray operator

C- Initial observations in pre-electro-spray tests

By considering these information, 15, 20, and $25 \mathrm{kV}$ were selected. By increasing the voltage to $20 \mathrm{kV}$, drop forming operation converts from emitters to jet cone. It should be noted that achieving to the cone-jet mode will provide constant and continuous process conditions. However, by increasing the voltage, the electric field becomes more severe, it cause jet instability and thus multi-jet spraying will take place. In the higher applied voltage, droplets will form more quickly and move faster to the foil surface, which could prevent complete evaporation of droplets, and therefore the number of large wet droplets will be greater.

\section{Effect of Ratio}

The ratio of shell solution flow rate to core solution flow rate also affects the quality of coaxial electrospray products.

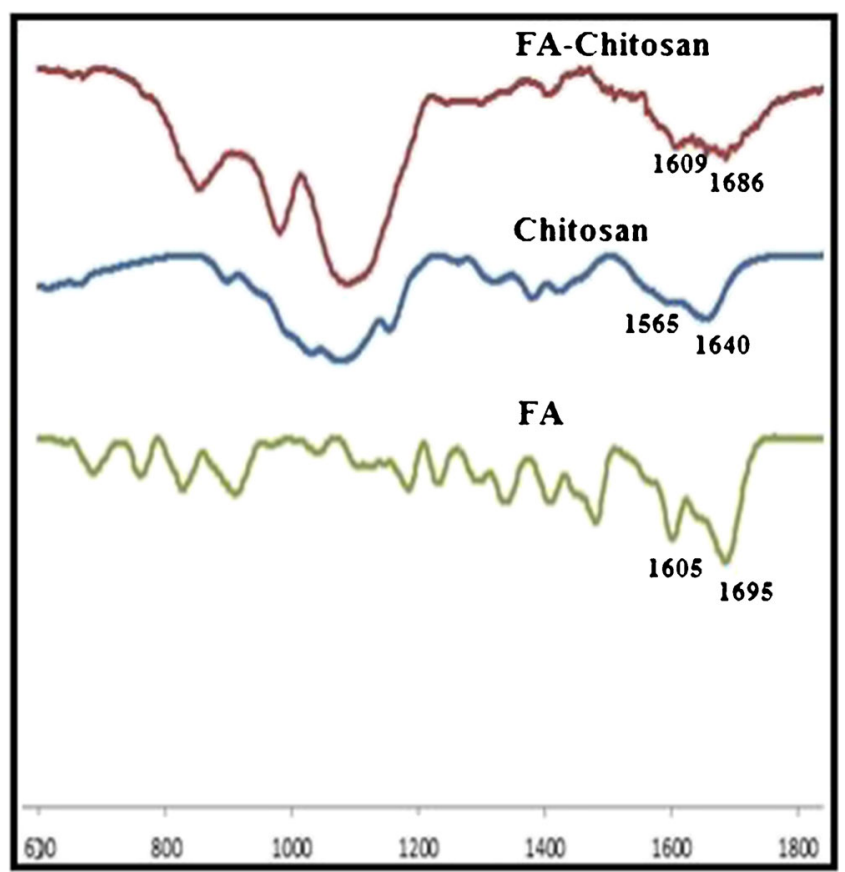

Wavelength $\left(\mathrm{cm}^{-1}\right)$

Fig. 4. IR spectra of FA-chitosan, chitosan and folic acid (FA) 
Table III. ANOVA Analysis for PS

Response $11 \quad Y_{1}$

ANOVA for response surface-reduced cubic model

Analysis of variance table (partial sum of squares-type III)

\begin{tabular}{llllll}
\hline \multicolumn{1}{c}{ Source } & Sum of squares & df & Mean square & $F$ value & $P$ value prob $>F$ \\
\hline Model & 13381.29 & 11 & 1216.48 & 138.72 & 0.0009 \\
A-voltage (v) & 12.25 & 1 & 12.25 & 1.40 & 0.3224 \\
B-ratio & 4.00 & 1 & 4.00 & 0.46 & 0.5478 \\
C-concentration (\%) & 1681.00 & 1 & 1681.00 & 191.69 & 0.0008 \\
AB & 2970.25 & 1 & 2970.25 & 338.71 & 0.0004 \\
AC & 1482.25 & 1 & 1482.25 & 169.03 & 0.0010 \\
BC & 2704.00 & 1 & 2704.00 & 308.35 & 0.0004 \\
$A^{2}$ & 175.07 & 1 & 175.07 & 19.96 & 0.0209 \\
$B^{2}$ & 308.62 & 1 & 308.62 & 35.19 & 0.0096 \\
$A^{2} B$ & 465.13 & 1 & 465.13 & 53.04 & 0.0053 \\
$A^{2}$ C & 4095.13 & 1 & 4095.13 & 466.99 & 0.0002 \\
AB ${ }^{2}$ & 512.00 & 1 & 512.00 & 58.39 & 0.0047 \\
Residual & 26.31 & 3 & 8.77 & & 0.4380 \\
Lack of fit & 8.31 & 1 & 8.31 & 0.92 & Not significant \\
Pure error & 18.00 & 2 & 9.00 & & \\
Cor total & 13407.60 & 14 & & & \\
\hline
\end{tabular}

Different ratios of flow rates between core and shell solutions were defined experimentally in order to achieve appropriate encapsulation conditions and stable cone-jet. In the solution flow rates of less than 1:2 (core/shell), a sufficient amount of shell solution does not exist to encompass the core solution. Ratios between $1: 3$ and 1:5 provide favorable conditions for the formation of stable Taylor cone-jet, and thus enable the ability to achieve adequate core-shell nanoparticles. Whereas by increasing the shell flow rate, yield of encapsulation was reduced and even a stable cone-jet may be difficult to achieve. As a result, the core flow rate was fixed at $0.1 \mathrm{~mL} / \mathrm{h}$, and the range between 0.3 and $0.5 \mathrm{~mL} / \mathrm{h}$ was set for shell flow rates.

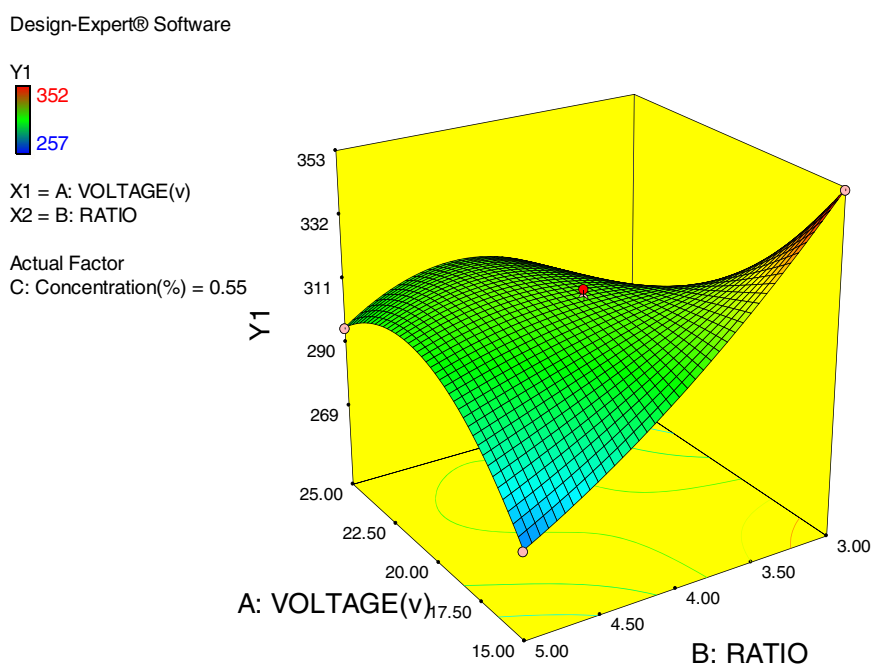

\section{Effect of Other Parameters}

Effect of Distance. The distance between the nozzle and aluminum foil also has a similar situation with the voltage factor (54). Ten, 15 and $20 \mathrm{~cm}$ of distance were used. If the distance is too small, the solvent does not find enough time to evaporate completely, thus droplets do not evaporate before reaching the collector and wet droplets can be seen on the surface of the aluminum foil. If the distance is chosen at more than $20 \mathrm{~cm}$, the encapsulated particles dispersed. This means more time, more materials, and of course more money should be spent. As a result of these experiments, which were identified in the pre-tests, the optimal conditions

Fig. 5. Counter plots and $3 \mathrm{D}$ graphs of ratio $(B)$ and voltage $(A)$ versus $\mathrm{PS}$

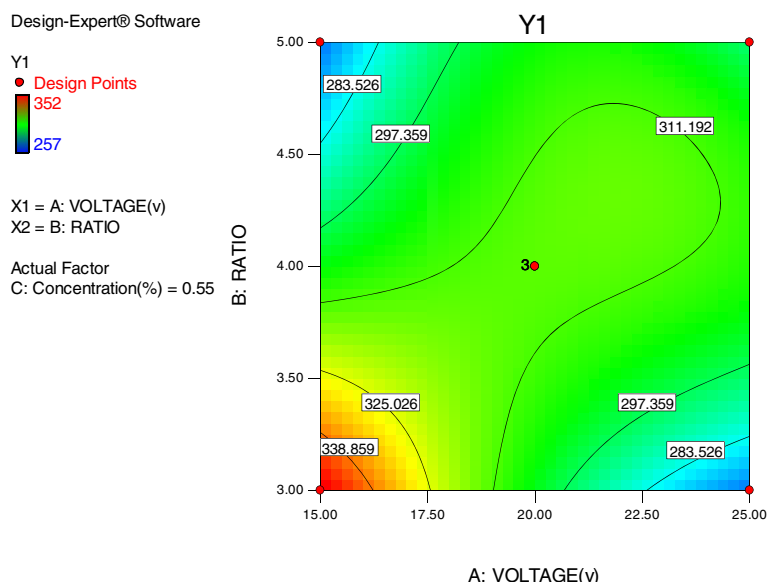


Design-Expert@ Software
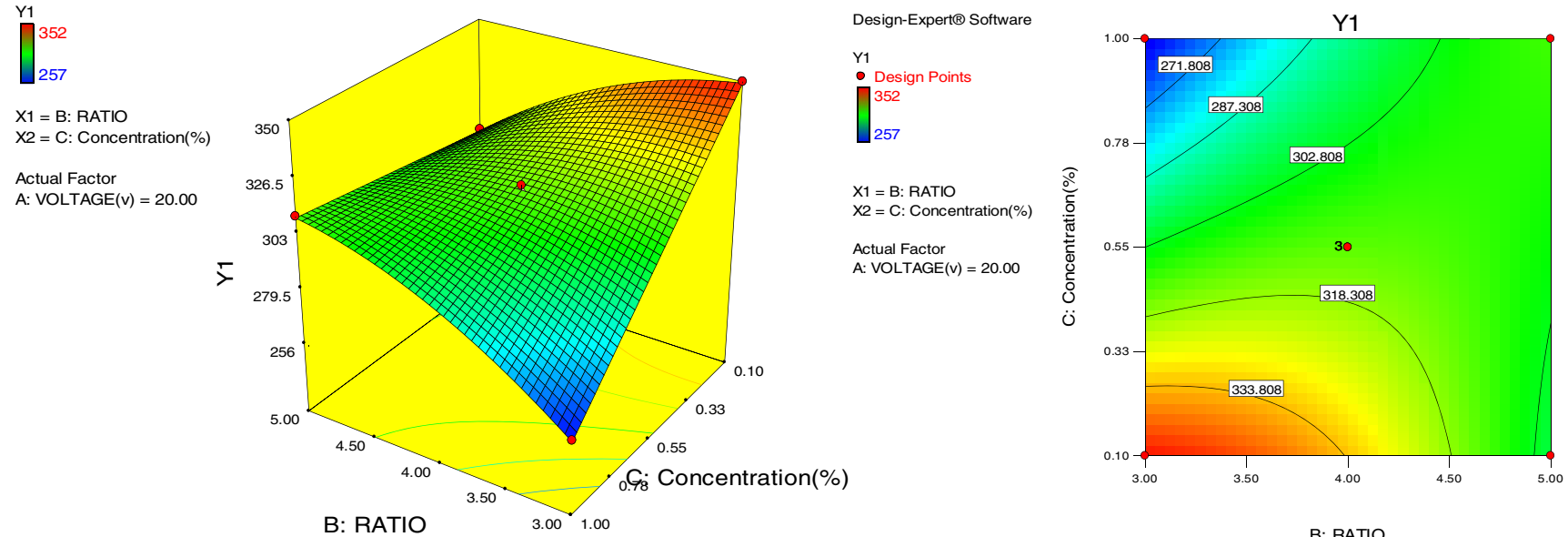

B: RATIO

Fig. 6. Counter plots and $3 \mathrm{D}$ graphs of ratio $(B)$ and concentration $(C)$ versus PS

occurred at a distance of $15 \mathrm{~cm}$. Therefore, $15 \mathrm{~cm}$ was selected and fixed in all experiments.

Effect of Nozzle Size. Effect of nozzle diameter was investigated previously, and the results showed that nozzle size was not an important parameter (53). Thus, in order to prepare ideal core-shell nanoparticles, the needle diameters chosen were 0.6 and $1.2 \mathrm{~mm}$ as inner and outer needle size, respectively.

\section{Effect of Formulation Parameters on PS}

The size of the gaps between leaking endothelial cells has been reported to be ranging between 380 and $780 \mathrm{~nm}$ in different tumors (55). On the other hand, in comparison with the small pore distance between the normal vascular endothelial cells (which is about 5 to $10 \mathrm{~nm}$ ), the significant difference

Design-Expert@ Software

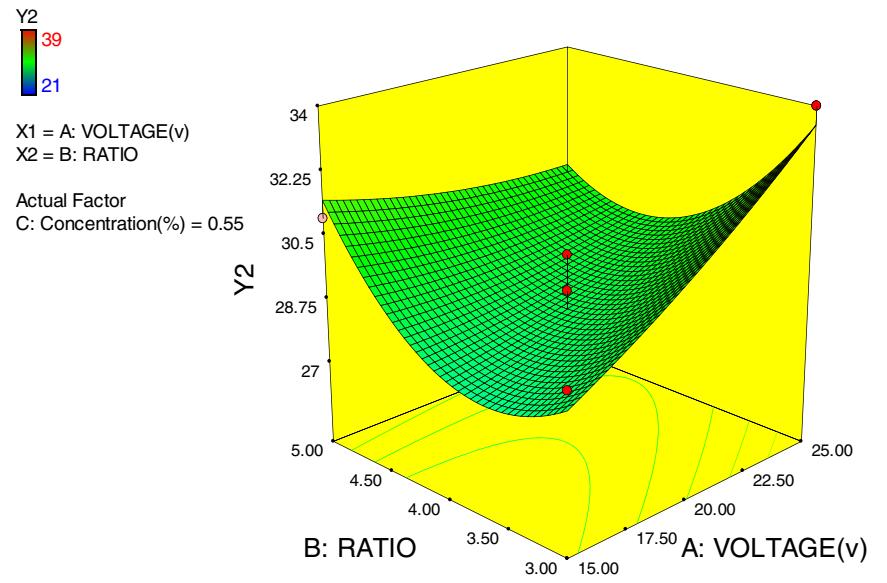

between the pore size of tumor endothelial cells and normal cells can be seen. Therefore, nanoparticles with specified sizes must have the ability to pass through the pores of leaky tumor endothelium and do not enter normal tissues, and as a result, increase in the concentration of nanoparticles in the tumor site will happen by considering enhanced permeability and retention effect (EPR) (56). The best particle size range has been reported as 10 to $400 \mathrm{~nm}$ (57-60). With these interpretations, the nanoparticles' size is an important factor and achieving the ideal particle size formed the most important goal of this study. Hence, the aim of optimizing for particle size was considered the minimum value. By considering multiple linear regression analysis, $Y_{1}$ equation is given as below:

$$
\begin{aligned}
Y_{1}= & 312.92+1.75 A+B-20.50 C+27.25 A B-19.25 A C \\
& +26.00 B C-6.86 A^{2}-9.11 B^{2}-15.25 \mathrm{~A}^{2} B+45.25 A^{2} C-16.00 B^{2} A
\end{aligned}
$$

Predictive ability of the model was indicated by the calculation of $R^{2}$ coefficients, which is a criterion of the
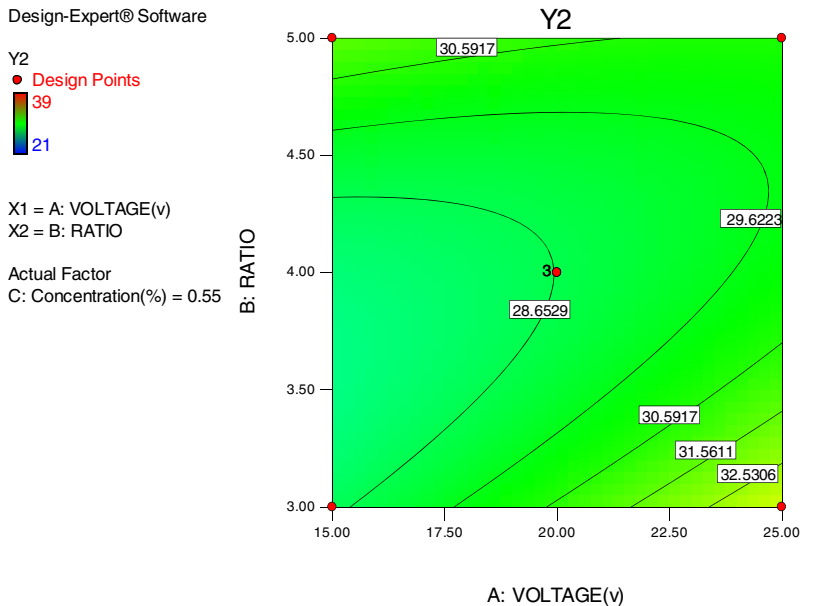

Fig. 7. Counter plots and 3D graphs of ratio $(B)$ and applied voltage $(A)$ versus PSD 
Table IV. ANOVA Analysis for PSD

Response $2 \quad Y_{2}$

ANOVA for response surface-reduced cubic model

Analysis of variance table (partial sum of squares-type III)

\begin{tabular}{llllll}
\hline \multicolumn{1}{c}{ Source } & Sum of squares & df & Mean square & $F$ value & $P$ value prob $>F$ \\
\hline Model & 237.73 & 11 & 21.61 & 9.73 & 0.0433 \\
A-voltage (v) & 4.00 & 1 & 4.00 & 1.80 & 0.2722 \\
B-ratio & 0.00 & 1 & 0.00 & 0.00 & 1.0000 \\
C-concentration (\%) & 0.00 & 1 & 0.00 & 0.00 & 1.0000 \\
$\mathrm{AB}$ & 9.00 & 1 & 9.00 & 4.05 & 0.1377 \\
$\mathrm{AC}$ & 156.25 & 1 & 156.25 & 70.31 & 0.0036 \\
$\mathrm{BC}$ & 16.00 & 1 & 16.00 & 7.20 & 0.0748 \\
$\mathrm{~A}^{2}$ & 0.31 & 1 & 0.31 & 0.14 & 0.7320 \\
$\mathrm{~B}^{2}$ & 15.39 & 1 & 15.39 & 6.93 & 0.0782 \\
$\mathrm{C}^{2}$ & 0.16 & 1 & 0.16 & 0.072 & 0.3210 \\
$\mathrm{~A}^{2} \mathrm{C}$ & 3.13 & 1 & 3.13 & 1.41 & 0.0379 \\
AC & 28.12 & 1 & 28.12 & 12.66 & 0.4523 \\
Residual & 6.67 & 3 & 2.22 & & Not significant \\
Lack of fit & 2.00 & 1 & 2.00 & 0.86 & \\
Pure error & 4.67 & 2 & 2.33 & & \\
Cor total & 244.40 & 14 & & & \\
\hline
\end{tabular}

model fitting. For all experimented batches, the $Y_{1}$ (particle size response) value showed good R-squared 0.9980 . However, report of this number is not enough to verify the model, and therefore the analysis of variance (ANOVA) reports are also important (Table III). If the $P$ value is less than 0.05 , it indicates the proper fitting of data with model, but if the lack of fit $P$ value became greater than 0.05 it showed that data adapted with model. The calculated $P$ value for lack of fit is 0.4380 , and this means that data has been fitted with model. The importance of a mathematical model is assessed by analysis of variance.

As it is seen in the equation, independent variables $A$, $C$, and $B$ have $P$ value less than 0.05 which significantly affect the particle size. Due to negative coefficient of $C$, it can be concluded by increasing the concentration of chitosan in the folic acid-chitosan solution, the particle size decreases. Furthermore, the influence of the variable depends on the value of its coefficient. But then, particle size had a relationship with the second order of $A$ and $B$, and by considering to their negative coefficients it could be concluded that by increasing the value of these variables separately, the particle size would be decreased. The interaction terms ( $\mathrm{BB}, \mathrm{AC}, \mathrm{BC}, \mathrm{A}^{2} \mathrm{~B}, \mathrm{~A}^{2} \mathrm{C}$ and $\left.\mathrm{B}^{2} \mathrm{~A}\right)$ showed how particle size changes when two independent variable simultaneously changed. The values of coefficients in the equation represent the effect of that term on the particle size. As can be seen in Fig. 5, by drawing a linear

Design-Expert@ Software
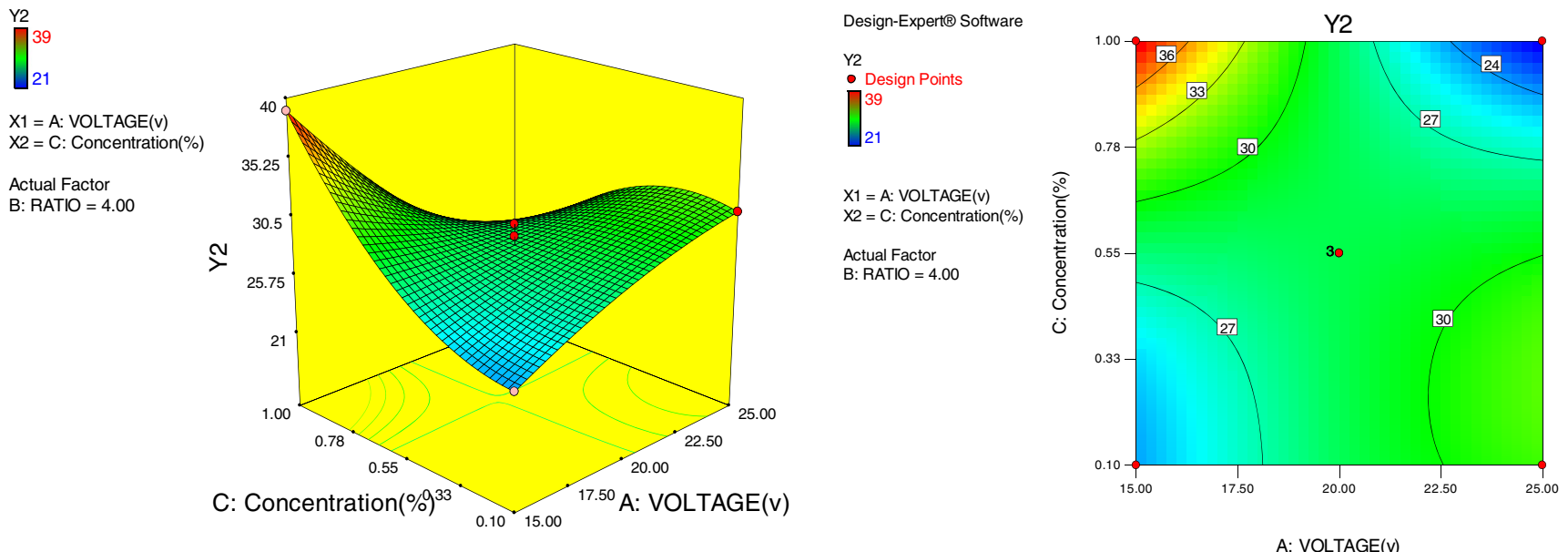

Fig. 8. Counter plots and $3 \mathrm{D}$ graphs of applied voltage $(A)$ and concentration $(C)$ versus PSD 
Table V. Results of Regression Analysis for $Y_{1}$ and $Y_{2}$

\begin{tabular}{lll}
\hline Regression statics for & & $Y_{1}$ \\
\hline Std. Dev. & 2.961289 & 1.490712 \\
Mean & 304.4 & 29.8 \\
C.V. $\%$ & 0.972828 & 5.002389 \\
PRESS & 1762.74 & $\mathrm{~N} / \mathrm{A}$ \\
R-Squared & 0.998038 & 0.972722 \\
Adj R-Squared & 0.990843 & 0.872704 \\
Pred R-Squared & 0.868527 & $\mathrm{~N} / \mathrm{A}$ \\
Adeq Precision & 36.38999 & 13.50000 \\
Equations & & \\
$y_{1}=312.92+1.75 A+B-20.50 C+27.25 A B-19.25 A C+26.00 B C-6.86 A^{2}-9.11 B^{2}-15.25 A^{2} B+45.25$ & $A^{2} C-16.00 B^{2} A$ \\
$Y_{2}=28.67+\mathrm{A}-1.50 \mathrm{AB}-6.25 A C+2.00 \mathrm{BC}+0.29 A^{2}+2.04 B^{2}-0.21 A^{2}-1.25 A^{2} C-3.75 c^{2} A$ & \\
\hline
\end{tabular}

regression, it could be concluded that by increasing the applied voltage (A), the particle size (PS) decreased. But, this is a curve diagram and the maximum of particle size was obtained at the moderate level of applied voltage. Since selected range is a certain range in order to form Taylor cone-jet, thus, it can be said near $25 \mathrm{kV}$ smaller particles are formed. By analyzing the ratio of outer solution to inner solution flow rate (B) factor from Figs. 5 and 6 graphs, it can be concluded by increasing the value of this term, the particle size decreased. The minimum particle size is obtained in the maximum value of this factor. As it is seen from $3 \mathrm{D}$ graphs and contour plots (Figs. 6 and 7), by increasing the concentration of chitosan in chitosan-folic acid solution, the particles become smaller. This conclusion proves that by adding molecular branches (folic acid molecules) on the surface of chitosan polymer, the values of nanoparticles size (which were coated with these kinds of polymers) become bigger in comparison with nonconjugated chitosan. On the other hand, researches have shown the in vitro results of chitosan-methotrexate (as an anticancer agent) nanoparticles had no sensible difference with free methotrexate (32). Considering both active and passive targeting are the main reasons of preparing targeted nanoparticles. As a result, producing of nanoparticles containing targeted agent branches which have the ability to reach the tumor interstitium area becomes important. The range of mean particle size of produced particles tolerated from 257 to $352 \mathrm{~nm}$ for all examined batches. Reported range is acceptable in order to enter the tumors.

\section{Effect of Formulation Parameters on PSD}

Achieved values for particle size proved the ability of these nanoparticles to enter tumor cells, but the accumulation of drug molecules in the tumor site is not just the only important factor. The other important factor is PSD. PSD defines the number of suitable nanoparticles which can pass through pores of tumor cells than the whole produced particles. Suitable nanoparticles have a diameter less than $400 \mathrm{~nm}$. On the other hand, evidences have shown that particles with diameters less than $100 \mathrm{~nm}$ are not well encapsulated. Thus, a range of 100 to $400 \mathrm{~nm}$ was selected for the suitable particle diameter. Accordingly, the aim of optimizing for PSD was considered the maximum value. By considering multiple linear regression analysis, $Y_{2}$ equation is given as below:

$$
\begin{aligned}
Y_{2}=28.67 & +\mathrm{A}-1.50 \mathrm{AB}-6.25 \mathrm{AC}+2.00 \mathrm{BC}+0.292 \mathrm{~A}^{2} \\
& +2.042 \mathrm{~B}^{2}-0.21 \mathrm{C}^{2}+1.25 A^{2} \mathrm{C}-3.75 \mathrm{C}^{2} \mathrm{~A}
\end{aligned}
$$

Table VI. Solutions for Optimum Formulations

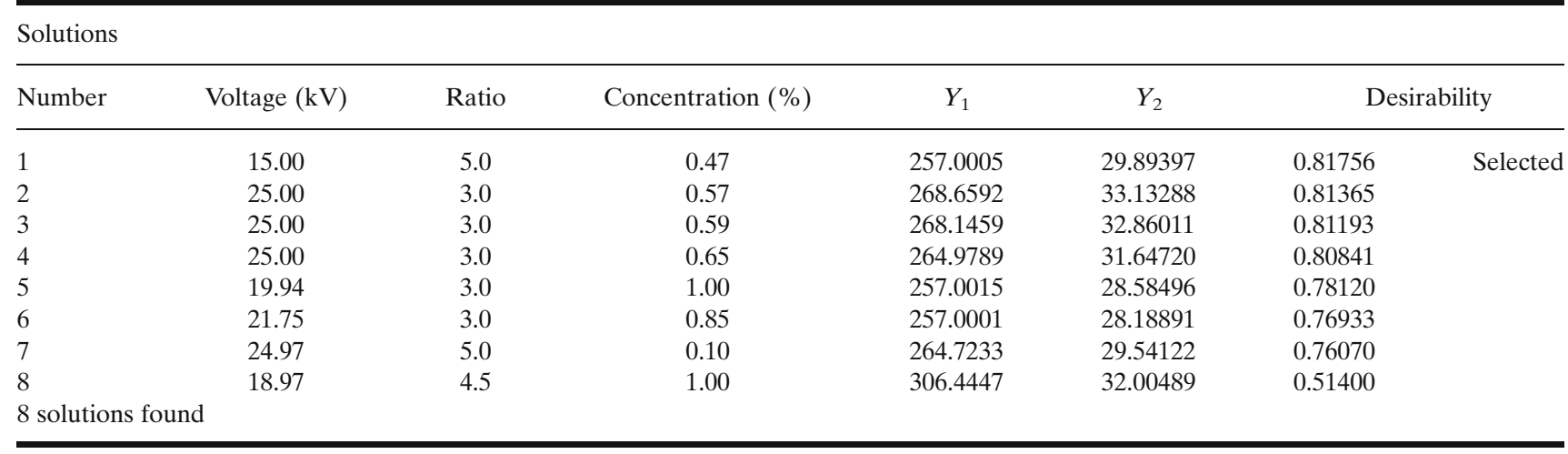




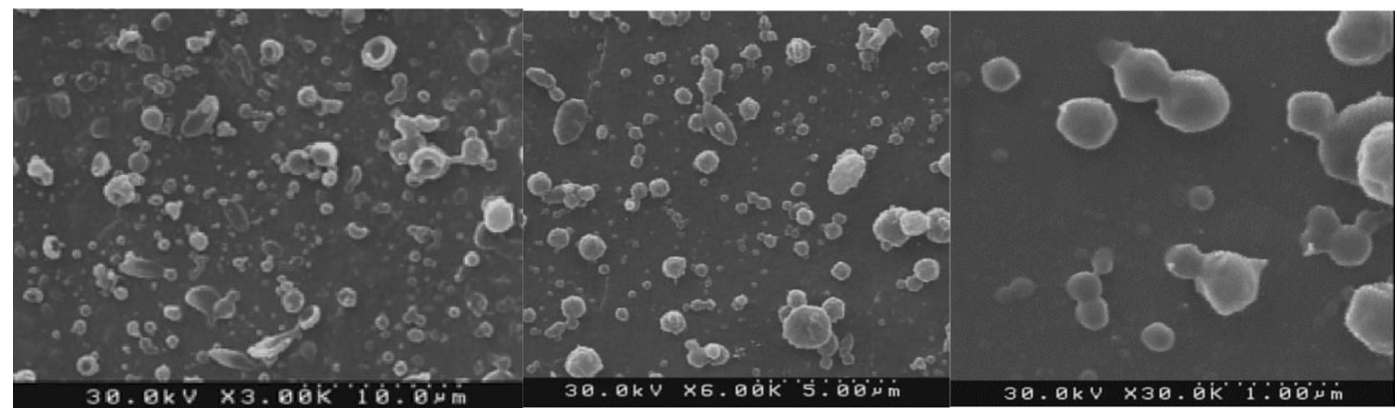

Fig. 9. FE-SEM-captured pictures in three different scales from optimized formulation

For all experimented batches, the $Y_{2}$ (PSD response) value showed good R-squared 0.9727. The ANOVA results showed in Table IV as well. The calculated $P$ value for lack of fit is 0.4523 , and this indicates that data has been fitted with model.

As it is seen in the equation, just factor $A$ has a $P$ value less than 0.05 . Due to positive coefficient of $A$, it can be concluded that by increasing the applied voltage, the PSD increases as well. PSD varies with the second order of $A, B$, and $C$. The interaction terms ( $\mathrm{AB}, \mathrm{AC}$, $\mathrm{BC}, \mathrm{A}^{2} \mathrm{C}$, and $\mathrm{C}^{2} \mathrm{~A}$ ) showed how PSD changes when two independent variable simultaneously changed. The values of coefficients in the equation represent the effect of that term on the PSD. In order to analyze the equation, putting points in the equation and drawing related graphs are required. With the drawing of 3D graphs and counter plots by Design expert software (Figs. 7 and 8), it can be seen that by increasing the applied voltage (A), the PSD increases significantly as well. By analyzing the ratio of outer solution to inner solution flow rates (B) factor from the plots of Fig. 7, it can be concluded that this term acted as a curve so that it has its minimum value at moderate ratios and it shows greater values at the upper and lower limit. As it can be seen from 3D graphs and contour plots (Fig. 8), by increasing the concentration of chitosan in FA-Chi solution, the number of favorable particles increases. The range of PSD tolerated from 21 to 39 present for all examined batches. The overall analyses showed that just around $29 \%$ of all produced particles had the requirement conditions. This means that just around $29 \%$ of drug dosage could reach the tumor interstitium and other particles do not have the ability to enter the tumor area (Table V).

\section{Optimization, Validation, and Evaluation}

Formulations have been published by Design expert as optimized solution (Table VI). These formulations have been calculated and analyzed by mathematical model. A formulation which had the best desirability factor and also had better process conditions has been selected. In the purpose of validation, the optimized conditions have been provided. Solutions were prepared according to new specified conditions and core-shell nanoparticles were prepared by coaxial electrospray process. In order to gain better results, three samples have been made. The new drug loaded nanoparticles were collected on the surface of the aluminum foils. The aluminum foils which were covered with sprayed particles were brought to analyze with FE-SEM (Fig. 9). The captured photos of all three samples have been analyzed by Image J software in order to measure particle size. The experimental results compared with estimated results in Table VII. Errors of $2.5 \%$ for PS and about $2.3 \%$ for PSD show the experiments and data optimization methodology were acceptable with a good approximation.

\section{Drug Loading and Encapsulation Efficiency}

DL and EE were approximately $4.56 \pm 0.15 \%$ and $89.6 \pm 3.8 \%$ (triplicate), respectively. In comparison, 41.6 $\pm 2.7 \%$ (triplicate) MTX was encapsulated into the FAChi-MTX NPs and DL was $2.78 \pm 0.11 \%$ (triplicate). The EE value and DL value were the mean of three batches.

We strongly believed that the presence of a polymeric carrier shell at the interface of the core layer was the main reason of enhancement of DL and EE. This layer prevented drug molecules from diffusing out of the core. Thus, such coreshell system with appropriate drug EE promises the prospect for a practically useful drug delivery system.

\section{In Vitro Release Studies}

The in vitro drug release studies of FA-Chi-MTX NPs are shown in Fig. 10. The release profile of nanoparticles in $\mathrm{PBS}$ checked at $\mathrm{pH}=7.4$ and $\mathrm{pH}=5$. A free MTX was

Table VII. Comparison of Experimental Values with Predicted Values

\begin{tabular}{llllrr}
\hline & A & B & C & Mean experimental value & Estimated value \\
\hline PS & 15 & 5 & 0.47 & 263.8 & 257.0005 \\
PSD & 15 & 5 & 0.47 & 30.6 & 2.577 \\
\hline
\end{tabular}

$P S$ particle size, $P S D$ particle size distribution 


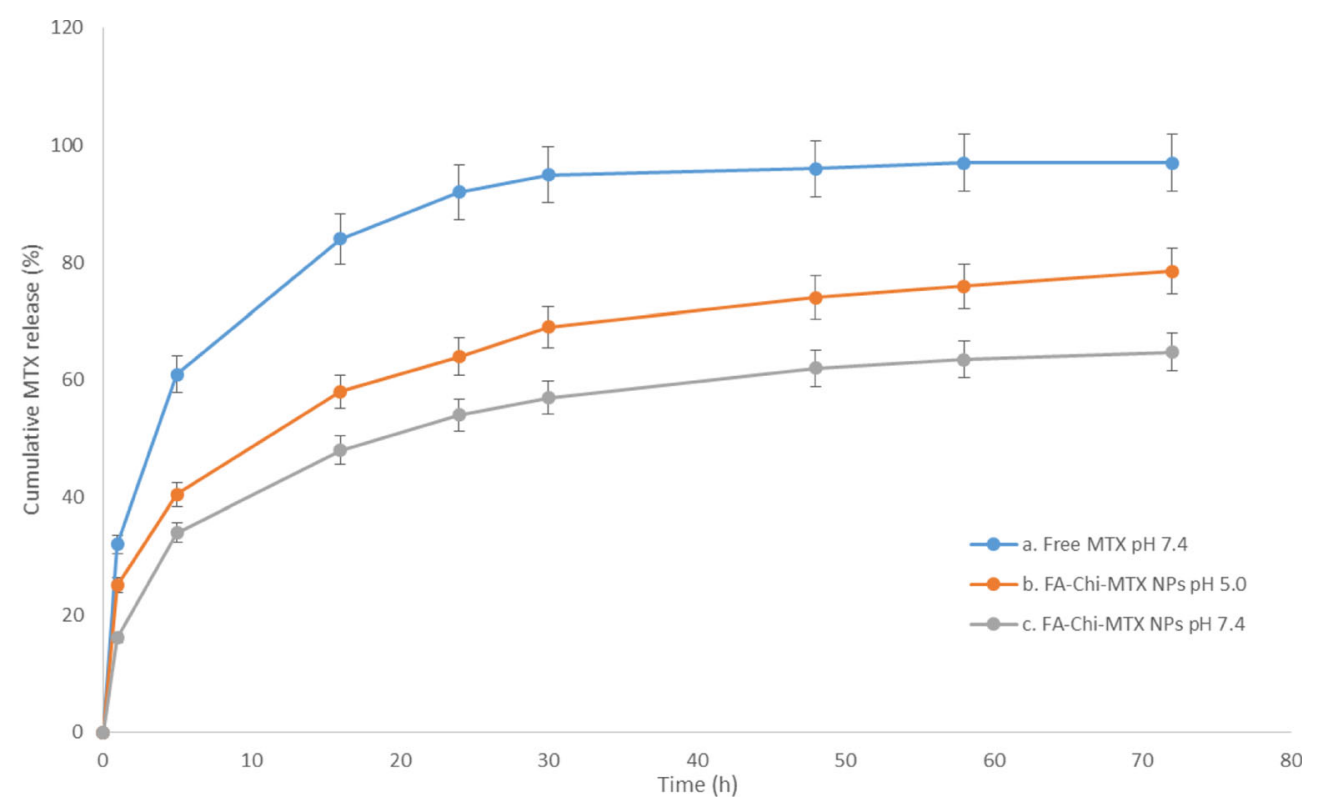

Fig. 10. In vitro cumulative MTX release in PBS at reported $\mathrm{pH}$. $a$ Free MTX at $\mathrm{pH}$ 7.4. $b$ FA-Chi-MTX NPs at $\mathrm{pH}$ 5.0. $c$ FA-Chi-MTX NPs at $\mathrm{pH} 7.4$

carried out at $\mathrm{pH} 7.4$ and complete diffusion across the dialysis membrane was occurred within $3 \mathrm{~h}$. Release studies of MTX throw FA-Chi-MTX NPs at pH 7.4, showed an initial burst release of $34.0 \%$ in $5 \mathrm{~h}$, and the total drug release in $72 \mathrm{~h}$ was $65 \%$. On the other hand, at $\mathrm{pH} 5.0$, a faster release of MTX throw prepared NPs appeared. The result was as follows: an initial burst of $40.5 \%$ in $5 \mathrm{~h}$, the gist of this test happened in the first $1 \mathrm{~h}$ the drug release achieved $25 \%$. This means that these NPs can throwback the growth of cancer cells in the very first penetration and especially in the short time. The cumulative release reached $78.5 \%$ in the following $72 \mathrm{~h}$. This release profile presents the possibility to fight against cancer cells continually.

MTX release was accelerated in $\mathrm{pH} 5.0$ in comparison with that at $\mathrm{pH} 7.4$, which confirms that MTX drug delivery is triggered at tumor extracellular site (61). The increase of MTX release at $\mathrm{pH} 5.0$ supports the increased intracellular drug delivery among the endosomes sites. These differences could be summarized into two main factors. The first one is

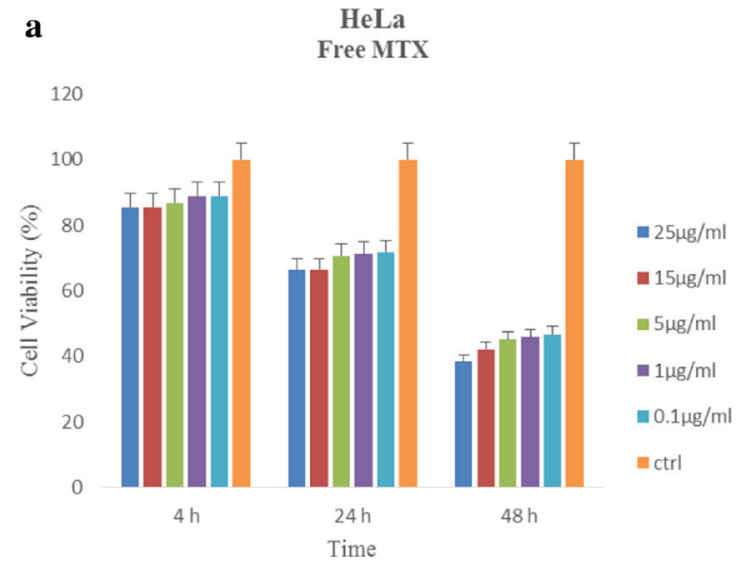

NPs' structure decomposition in lower $\mathrm{pH}$ (51), and the second one might be due to the lower degree of MTX ionization under acidic medium (62). It is extremely important to avoid multidrug resistance (MDR) of initially sensitive tumor cells caused by slow release at the site of action by development of slow release to rapid release kinetics when the target sites have been reached (61).

\section{Cytotoxicity Studies}

Methotrexate and MTX-loaded NPs cell cytotoxicities were evaluated using MTT assay. The HeLa cells were incubated with MTX at drug concentrations of $0.1,1,5,15$, and $25 \mu \mathrm{g} / \mathrm{mL}$ after 4, 24, and $48 \mathrm{~h}$; cell inhibition treatment was measured and shown in Fig. 11a. It is obvious the higher drug concentration will cause higher mortality of the cells (less survival rate). Also, for the cytotoxicity of FA-Chi-MTX NPs, the same drug concentrations $(0.1,1,5,15,25 \mu \mathrm{g} / \mathrm{mL})$ were applied. After scheduled time intervals (4, 24, 48 h) treatment, the cell inhibition were found (Fig. 11b).

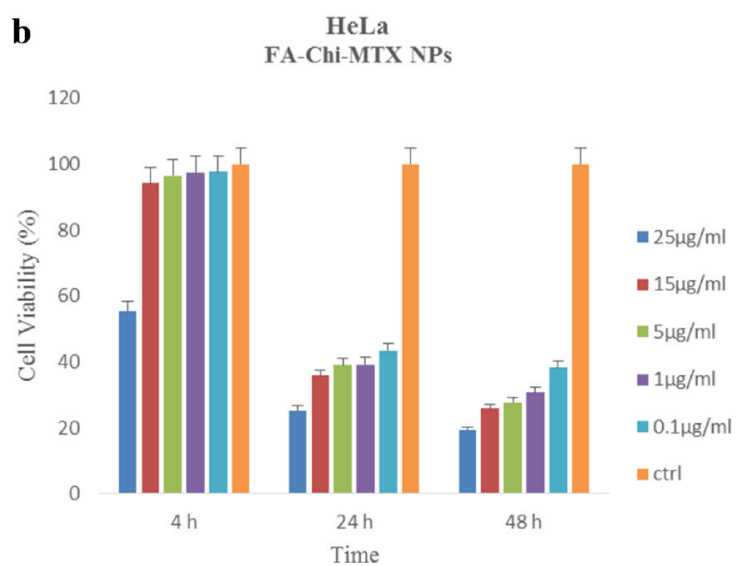

Fig. 11. Cytotoxicity studies on HeLa tumor cell lines. a Free MTX at the $0.01-25 \mu \mathrm{g} / \mathrm{mL}$ concentration range as determined by MTT assay. b FA-Chi loaded with MTX at the $0.01-25 \mu \mathrm{g} / \mathrm{mL}$ concentration range as determined by MTT assay 

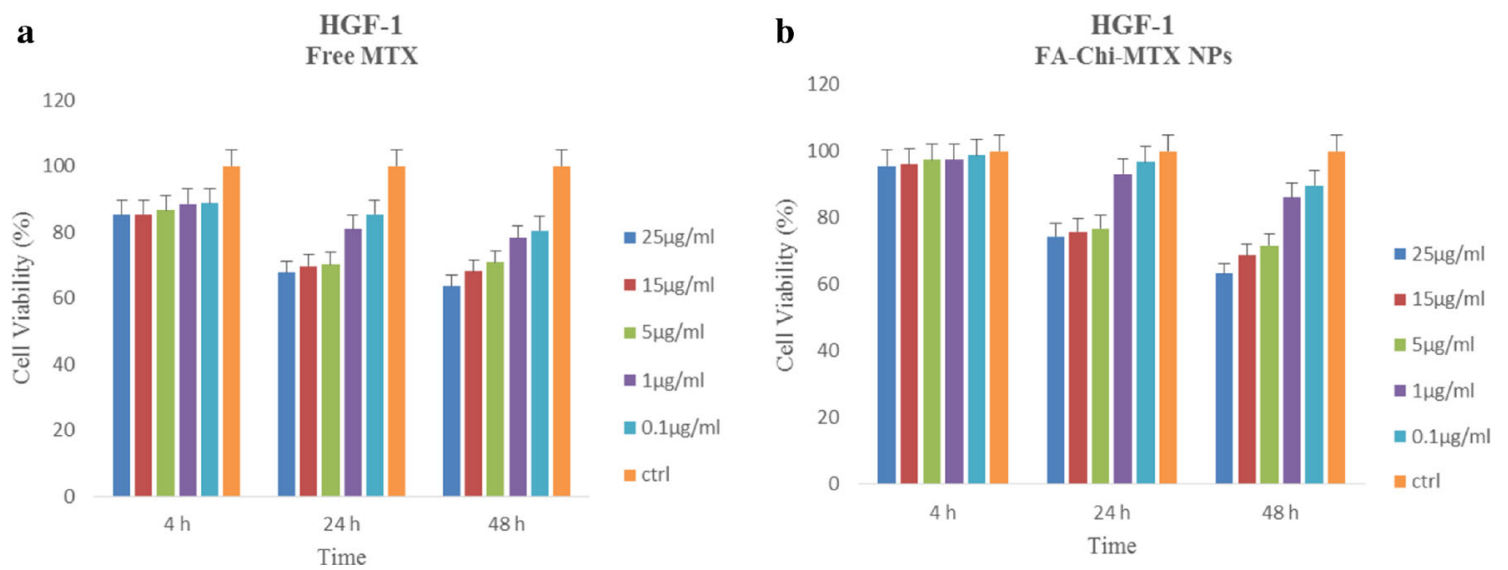

Fig. 12. Cytotoxicity studies on HGF-1 cell lines. a Free MTX at the $0.01-25 \mu \mathrm{g} / \mathrm{mL}$ concentration range as determined by MTT assay. b FA-Chi loaded with MTX at the $0.01-25 \mu \mathrm{g} / \mathrm{mL}$ concentration range as determined by MTT assay

The cytotoxicity of HGF-1 cells are shown in Fig. 12. The cell inhibition by MTX at drug concentrations of $0.1,1,5,15$, and $25 \mu \mathrm{g} / \mathrm{mL}$ after 4,24 , and $48 \mathrm{~h}$ is described in Fig. 12a, and the cytotoxicity of FA-Chi-MTX NPs were applied in Fig. 12b. The non-tumor HGF-1 cell line displayed lower sensitivity to the antiproliferative of both samples. In comparison, it is obvious that prepared site-specified MTX-loaded NPs demonstrated higher cytotoxicity than free MTX at the same conditions (drug concentration and time intervals). This means that the drug requirement of FA-Chi-MTX NPs could be less in comparison with free MTX for the same therapeutic effect and better treatment of tumor cells. The MTT assay results showed that the FA-Chi-MTX shell-core NPs may promise future researches pharmaceutical applications.

\section{CONCLUSION}

Preparation of multi-component nanoparticles formulation includes many factors and describing such systems is very complex. Considering all these factors at their optimal levels and achieving the best possible responses, a lot of experiments and many different testing combinations which included all available factors are needed.

Using Box-Behnken RSM can reduce the number of required experiments, produce beneficial results for the main effects and interactions between selected factors, and explain their complex interactions by drawing the graphs and plots. According to obtained results, the optimized conditions for producing desirable FA-Chi-MTX core-shell nanoparticles are provide in the concentration of $0.47(\mathrm{v} / \mathrm{v}) \%$ of chitosan solution and $0.53(v / v) \%$ of FA-chi solution with the flow rate ratio of 5:1 (shell/core solutions) and the applied voltage of $15 \mathrm{kV}$ in the coaxial electrospray process. As a result of providing these optimal conditions, the particles with the mean diameter of $257 \mathrm{~nm}$ and the particle size distribution around $30 \%$ are produced. Furthermore, the feasibility of using prepared NPs to target tumor extracellular $\mathrm{pH}$ was shown, as drug release was greater in the $\mathrm{pH}$ of endosome (acidic medium). This evidence showed acceptable hemocompatibility and imbursed cytotoxicity on tumor cell lines. On the other hand, comparison of prepared NPs release on HeLa tumor cell lines with that on HGF-1 normal cell lines showed a beneficial approach which provides enhanced anticancer efficacy at the tumor site. In conclusion, the current study is useful for successful DOE, development, and optimization of FA-Chi-MTX core-shell nanoparticles.

\section{ACKNOWLEDGMENTS}

The authors gratefully thank the Institute of Medicinal Plants and Pasteur Institute of Iran for all of the support provided.

\section{REFERENCES}

1. Calabresi P, Parks R. Alkylating agents, antimetabolites, hormones, and other antiproliferative agents. The pharmacological basis of therapeutics. New York: Macmillan; 1975. p. 1254-307.

2. Brunton L, Chabner B, Knollman B. Goodman and Gilman's The Pharmacological Basis of Therapeutics, Twelfth Edition: McGraw-Hill Education; 2011.

3. Cartwright R, Alexander F, McKinney P, Ricketts T. Leukaemia and lymphoma. 1990.

4. Chamberlain MC, Glantz MJ. Neurologic complications associated with intrathecal liposomal cytarabine given prophylactically in combination with high-dose methotrexate and cytarabine to patients with acute lymphocytic leukemia. 2007.

5. Jabbour E, O'Brien S, Kantarjian H, Garcia-Manero G, Ferrajoli A, Ravandi F, et al. Neurologic complications associated with intrathecal liposomal cytarabine given prophylactically in combination with high-dose methotrexate and cytarabine to patients with acute lymphocytic leukemia. 2007.

6. Ofner CM, Pica K, Bowman BJ, Chen C-S. Growth inhibition, drug load, and degradation studies of gelatin/methotrexate conjugates. Int J Pharm. 2006;308(1):90-9.

7. Tishler M, Caspi D, Graff E, Segal R, Peretz H, Yaron M. Synovial and serum levels of methotrexate during methotrexate therapy of rheumatoid arthritis. Rheumatology. 1989;28(5):422-3.

8. Gao X, Zhang X, Zhang X, Cheng C, Wang Z, Li C. Encapsulation of BSA in polylactic acid-hyperbranched polyglycerol conjugate nanoparticles: preparation, characterization, and release kinetics. Polym Bull. 2010;65(8):787-805.

9. Tang Y, Zhao Y, Li Y, Du Y. A thermosensitive chitosan/poly (vinyl alcohol) hydrogel containing nanoparticles for drug delivery. Polym Bull. 2010;64(8):791-804.

10. Vauthier C, Dubernet C, Chauvierre C, Brigger I, Couvreur P. Drug delivery to resistant tumors: the potential of poly (alkyl cyanoacrylate) nanoparticles. J Control Release. 2003;93(2):151-60. 
11. Jabr-Milane L, van Vlerken L, Devalapally H, Shenoy D, Komareddy S, Bhavsar M, et al. Multi-functional nanocarriers for targeted delivery of drugs and genes. J Control Release. 2008;130(2):121-8. doi:10.1016/j.jconrel.2008.04.016.

12. Torchilin VP. Multifunctional nanocarriers. Adv Drug Deliv Rev. 2006;58(14):1532-55. doi:10.1016/j.addr.2006.09.009.

13. Bao H, Li L, Zhang H. Influence of cetyltrimethylammonium bromide on physicochemical properties and microstructures of chitosan-TPP nanoparticles in aqueous solutions. J Colloid Interface Sci. 2008;328(2):270-7. doi:10.1016/j.jcis.2008.09.003.

14. Fan W, Yan W, Xu Z, Ni H. Formation mechanism of monodisperse, low molecular weight chitosan nanoparticles by ionic gelation technique. Colloids Surf B: Biointerfaces. 2012;90:21-7.

15. Vila A, Sánchez A, Janes K, Behrens I, Kissel T, Jato JLV, et al. Low molecular weight chitosan nanoparticles as new carriers for nasal vaccine delivery in mice. Eur J Pharm Biopharm. 2004;57(1):123-31.

16. Anitha A, Chennazhi K, Nair S, Jayakumar R. 5-Flourouracil loaded N, O-carboxymethyl chitosan nanoparticles as an anticancer nanomedicine for breast cancer. J Biomed Nanotechnol. 2012;8(1):29-42.

17. Arya N, Chakraborty S, Dube N, Katti DS. Electrospraying: a facile technique for synthesis of chitosan-based micro/ nanospheres for drug delivery applications. J Biomed Mater Res B Appl Biomater. 2009;88(1):17-31.

18. Fu J, Wang D, Wang T, Yang W, Deng Y, Wang H, et al. High entrapment efficiency of chitosan/polylactic acid/tripolyphotspate nanosized microcapsules for rapamycin by an emulsionevaporation approach. J Biomed Nanotechnol. 2010;6(6):725-8.

19. Kavya K, Dixit R, Jayakumar R, Nair SV, Chennazhi KP. Synthesis and characterization of chitosan/chondroitin sulfate/nano$\mathrm{SiO} 2$ composite scaffold for bone tissue engineering. J Biomed Nanotechnol. 2012;8(1):149-60.

20. Kim J, Lee CM, Jeong HJ, Lee KY. In vivo tumor accumulation of nanoparticles formed by ionic interaction of glycol chitosan and fatty acid ethyl ester. J Nanosci Nanotechnol. 2011;11(2):1160-6.

21. Narayanan D, Anitha A, Jayakumar R, Nair S, Chennazhi K. Synthesis, characterization and preliminary in vitro evaluation of PTH 1-34 loaded chitosan nanoparticles for osteoporosis. J Biomed Nanotechnol. 2012;8(1):98-106.

22. Shokrgozar MA, Mottaghitalab F, Mottaghitalab V, Farokhi M. Fabrication of porous chitosan/poly (vinyl alcohol) reinforced single-walled carbon nanotube nanocomposites for neural tissue engineering. J Biomed Nanotechnol. 2011;7(2):276-84.

23. Tallury P, Santra S, Sharma P, De Castro M, Maria B, Bengtsson $\mathrm{N}$, et al. Fluorescent and paramagnetic chitosan nanoparticles that exhibit high magnetic resonance relaxivity: synthesis, characterization and in vitro studies. J Biomed Nanotechnol. 2011;7(5):7249

24. Vural I, Sarisozen C, Olmez SS. Chitosan coated furosemide liposomes for improved bioavailability. J Biomed Nanotechnol. 2011;7(3):426-30.

25. Wang J, Tan H, Yu A, Ling P, Lou H, Zhai G, et al. Preparation of chitosan-based nanoparticles for delivery of low molecular weight heparin. J Biomed Nanotechnol. 2011;7(5):696-703.

26. Yang W, Fu J, Wang D, Wang T, Wang H, Jin S, et al. Study on chitosan/polycaprolactone blending vascular scaffolds by electrospinning. J Biomed Nanotechnol. 2010;6(3):254-9.

27. Yang W, Fu J, Wang T, He N. Chitosan/sodium tripolyphosphate nanoparticles: preparation, characterization and application as drug carrier. J Biomed Nanotechnol. 2009;5(5):591-5.

28. Mehrotra A, Nagarwal RC, Pandit JK. Lomustine loaded chitosan nanoparticles: characterization and in-vitro cytotoxicity on human lung cancer cell line L132. Chem Pharm Bull. 2011;59(3):315-20.

29. Trapani A, Denora N, Iacobellis G, Sitterberg J, Bakowsky U, Kissel T. Methotrexate-loaded chitosan-and glycolchitosan-based nanoparticles: a promising strategy for the administration of the anticancer drug to brain tumors. AAPS PharmSciTech. 2011;12(4):1302-11.

30. Kean T, Roth S, Thanou M. Trimethylated chitosans as non-viral gene delivery vectors: cytotoxicity and transfection efficiency. J Control Release. 2005;103(3):643-53.
31. Shahidi F, Synowiecki J. Isolation and characterization of nutrients and value-added products from snow crab (Chionoecetes opilio) and shrimp (Pandalus borealis) processing discards. J Agric Food Chem. 1991;39(8):1527-32.

32. Ji J, Wu D, Liu L, Chen J, Xu Y. Preparation, characterization, and in vitro release of folic acid-conjugated chitosan nanoparticles loaded with methotrexate for targeted delivery. Polym Bull. 2012;68(6):1707-20.

33. Kohler N, Sun C, Wang J, Zhang M. Methotrexate-modified superparamagnetic nanoparticles and their intracellular uptake into human cancer cells. Langmuir. 2005;21(19):885864.

34. Theti DS, Jackman AL. The role of $\alpha$-folate receptor-mediated transport in the antitumor activity of antifolate drugs. Clin Cancer Res. 2004;10(3):1080-9.

35. Chan P, Kurisawa M, Chung JE, Yang Y-Y. Synthesis and characterization of chitosan-g-poly (ethylene glycol)-folate as a nonviral carrier for tumor-targeted gene delivery. Biomaterials. 2007;28(3):540-9.

36. Bayram M, Ozogul C, Ercan ZS, Dilekoz E, Soyer C, Bayram O. Examination of the rescue effects of folic acid on derangement of the tubo-ovarian ultrastructural architecture caused by methotrexate. Adv Ther. 2006;23(5):772-7.

37. Cohen IJ. Defining the appropriate dosage of folinic acid after high-dose methotrexate for childhood acute lymphatic leukemia that will prevent neurotoxicity without rescuing malignant cells in the central nervous system. J Pediatr Hematol Oncol. 2004;26(3):156-63.

38. Cohen IJ. Prevention of high-dose-methotrexate neurotoxicity by adequate folinic acid rescue is possible even after central nervous system irradiation. Med Hypotheses. 2007;68(5):1147-53.

39. Leamon CP, Reddy JA. Folate-targeted chemotherapy. Adv Drug Deliv Rev. 2004;56(8):1127-41.

40. Zhao H, Yung LYL. Selectivity of folate conjugated polymer micelles against different tumor cells. Int J Pharm. 2008;349(1):256-68

41. Enayati M, Ahmad Z, Stride E, Edirisinghe M. One-step electrohydrodynamic production of drug-loaded micro- and nanoparticles. J R Soc Interface. 2010;7(45):667-75.

42. Grimm RL. Fundamental studies of the mechanisms and applications of field-induced droplet ionization mass spectrometry and electrospray mass spectrometry: California Institute of Technology. 2005.

43. Park S, Hwang S, Lee J. pH-responsive hydrogels from moldable composite microparticles prepared by coaxial electro-spray drying. Chem Eng J. 2011;169(1-3):348-57. doi:10.1016/ j.cej.2011.02.063.

44. Wu Y, Yu B, Jackson A, Zha W, Lee LJ, Wyslouzil BE. Coaxial electrohydrodynamic spraying: a novel one-step technique to prepare oligodeoxynucleotide encapsulated lipoplex nanoparticles. Mol Pharm. 2009;6(5):1371-9.

45. Zhang S, Kawakami K, Yamamoto M, Masaoka Y, Kataoka M, Yamashita S, et al. Coaxial electrospray formulations for improving oral absorption of a poorly water-soluble drug. Mol Pharm. 2011;8(3):807-13.

46. Guo W, Hinkle GH, Lee RJ. 99mTc-HYNIC-folate: a novel receptor-based targeted radiopharmaceutical for tumor imaging. J Nucl Med. 1999;40(9):1563-9.

47. Lee ES, Na K, Bae YH. Polymeric micelle for tumor $\mathrm{pH}$ and folate-mediated targeting. J Control Release. 2003;91(1):103-13.

48. Wan A, Sun Y, Li H. Characterization of folate-graft-chitosan as a scaffold for nitric oxide release. Int J Biol Macromol. 2008;43(5):415-21.

49. Yang S-J, Lin F-H, Tsai K-C, Wei M-F, Tsai H-M, Wong J-M, et al. Folic acid-conjugated chitosan nanoparticles enhanced protoporphyrin IX accumulation in colorectal cancer cells. Bioconjug Chem. 2010;21(4):679-89.

50. Zhang Z, Lee SH, Feng S-S. Folate-decorated poly (lactide-coglycolide)-vitamin E TPGS nanoparticles for targeted drug delivery. Biomaterials. 2007;28(10):1889-99.

51. Xu S, Xu Q, Zhou J, Wang J, Zhang N, Zhang L. Preparation and characterization of folate-chitosan-gemcitabine core-shell nanoparticles for potential tumor-targeted drug delivery. J Nanosci Nanotechnol. 2013;13(1):129-38. 
52. Melcher J, Taylor G. Electrohydrodynamics: a review of the role of interfacial shear stresses. Annu Rev Fluid Mech. 1969;1(1):111-46.

53. Zhang S, Kawakami K. One-step preparation of chitosan solid nanoparticles by electrospray deposition. Int J Pharm. 2010;397(1):211-7.

54. Tang K, Gomez A. Monodisperse electrosprays of low electric conductivity liquids in the cone-jet mode. J Colloid Interface Sci. 1996;184(2):500-11.

55. Hobbs SK, Monsky WL, Yuan F, Roberts WG, Griffith L, Torchilin VP, et al. Regulation of transport pathways in tumor vessels: role of tumor type and microenvironment. Proc Natl Acad Sci. 1998;95(8):4607-12.

56. Garinot M, Fiévez V, Pourcelle V, Stoffelbach F, des Rieux A, Plapied L, et al. PEGylated PLGA-based nanoparticles targeting M cells for oral vaccination. J Control Release. 2007;120(3):195204.
57. Alexis F, Pridgen E, Molnar LK, Farokhzad OC. Factors affecting the clearance and biodistribution of polymeric nanoparticles. Mol Pharm. 2008;5(4):505-15.

58. Allen TM, Cullis PR. Drug delivery systems: entering the mainstream. Science. 2004;303(5665):1818-22.

59. Jain RK. Transport of molecules, particles, and cells in solid tumors. Annu Rev Biomed Eng. 1999;1(1):241-63.

60. Soussan E, Cassel S, Blanzat M, Rico-Lattes I. Drug delivery by soft matter: matrix and vesicular carriers. Angew Chem Int Ed. 2009; 48(2):274-88.

61. Na K, Lee ES, Bae YH. Adriamycin loaded pullulan acetate/ sulfonamide conjugate nanoparticles responding to tumor $\mathrm{pH}$ : $\mathrm{pH}$-dependent cell interaction, internalization and cytotoxicity in vitro. J Control Release. 2003;3(13):87.

62. Daniele RN, Lorena T, Montserrat M, Lourdes PM, Rosa IM, Pilar V. In vitro antitumor activity of methotrexate via $\mathrm{pH}-$ sensitive chitosan nanoparticles. J Biomater. 2013;34:2758-72. 